\title{
Extending Emulsion Functionality: Post-Homogenization Modification of Droplet Properties
}

\author{
Long Bai ${ }^{1,2}$ and David Julian McClements ${ }^{2,3, *}$ \\ 1 College of Material Science and Engineering, Northeast Forestry University, Harbin 150040, China; \\ longbai2011@hotmail.com \\ 2 Biopolymers and Colloids Laboratory, Department of Food Science, University of Massachusetts, Amherst, \\ MA 01003, USA \\ 3 Department of Biochemistry, Faculty of Science, King Abdulaziz University, P. O. Box 80203, Jeddah 21589, \\ Saudi Arabia \\ * Correspondence: mcclements@foodsci.umass.edu; Tel.: +1-413-545-1019
}

Academic Editor: Andreas Håkansson

Received: 22 March 2016; Accepted: 9 May 2016; Published: 17 May 2016

\begin{abstract}
Homogenizers are commonly used to produce oil-in-water emulsions that consist of emulsifier-coated oil droplets suspended within an aqueous phase. The functional attributes of emulsions are usually controlled by selecting appropriate ingredients (e.g., surfactants, co-surfactants, oils, solvents, and co-solvents) and processing conditions (e.g., homogenizer type and operating conditions). However, the functional attributes of emulsions can also be tailored after homogenization by manipulating their composition, structure, or physical state. The interfacial properties of lipid droplets can be altered using competitive adsorption or coating methods (such as electrostatic deposition). The physical state of oil droplets can be altered by selecting an oil phase that crystallizes after the emulsion has been formed. The composition of the disperse phase can be altered by mixing different kinds of oil droplets together to induce inter-droplet exchange of oil molecules. The local environment of oil droplets can be altered by embedding them within hydrogel beads. The aggregation state of oil droplets can be controlled by promoting flocculation. These post-homogenization methods can be used to alter functional attributes such as physical stability, rheology, optical properties, chemical degradation, retention/release properties, and/or gastrointestinal fate.
\end{abstract}

Keywords: homogenization; post-homogenization; electrostatic deposition; emulsions; nanoemulsions; hydrogels; solid lipid nanoparticles

\section{Introduction}

Oil-in-water emulsions and nanoemulsions are commonly used in the food, cosmetics, health care, supplement and pharmaceutical industries to encapsulate, protect, and release non-polar compounds [1-4]. These non-polar compounds may be nutrients, nutraceuticals, vitamins, antioxidants, antimicrobials, colors, flavors, or drugs. The non-polar compounds may form the entirety of the disperse phase within an emulsion (e.g., fish, flaxseed, essential, or flavor oils) or they may be dissolved in carrier oils (e.g., carotenoids or vitamins dissolved in corn oil). The physicochemical properties, sensory attributes, and gastrointestinal fate of oil-in-water emulsions depend on their microstructure and composition $[5,6]$. Consequently, emulsions with different functional attributes can be fabricated by carefully controlling their microstructure and composition. This is usually achieved by selecting specific components to formulate the emulsion (such as surfactants, co-surfactants, oils, 
solvents, and co-solvents) and specific homogenization conditions to form the emulsion (such as homogenizer type and operating conditions) [7-11].

However, in many instances it is not possible to create emulsion droplets with the desirable functional attributes using conventional ingredients and homogenization methods, and therefore it is necessary to tailor the properties of the droplets after they have been produced by homogenization. The optical properties, rheology, stability, release characteristics, and gastrointestinal fate of oil-in-water emulsions depend on the composition, size, charge, and physical state of the droplets they contain [6]. Consequently, it is possible to modulate these physicochemical and physiological properties by post-homogenization modification of droplet properties, thereby tailoring their functional attributes for specific applications. The potential of these post-homogenization methods is highlighted with a few examples:

- Some homogenization methods are only capable of producing small droplets using certain types of oils and surfactants. However, these components may not have the desired functional attributes, e.g., the surfactant used to form the emulsion may not lead to droplets that are stable over the intended range of environmental conditions the emulsion will experience in a commercial application. Consequently, it may be necessary to form an emulsion using one type of surfactant, and then exchange the surfactant afterwards.

- Most homogenization methods require that the lipid phase be liquid during emulsion formation. However, for certain applications it is an advantage to have a lipid phase that is solid in the final product (e.g., to improve chemical stability or modulate release profiles). This may be achieved by using a lipid phase that is liquid at high temperatures, but that is solid at the intended temperature of utilization. The emulsion can then be homogenized at high temperatures, and then cooled afterwards.

- Some homogenization methods are limited in the smallest size of droplets that they can produce due to mechanical limitations. For certain commercial applications it may be important to have very small droplets so as to create products that are optically transparent or that have high oral bioavailability. In this case, it may be possible to use a post-homogenization method to further reduce the size of the droplets in an emulsion after it has been produced.

- In some research applications it is useful to have emulsions that all have the same droplet size distribution, but that have different interfacial properties, such as charge. This can be achieved by creating one type of oil-in-water emulsion using a certain type of emulsifier, and then exchanging the original emulsifiers from the droplet surfaces afterwards.

The purpose of this review article is to highlight the potential of post-homogenization methods for altering the properties of the droplets in emulsions so that they can be tailored for specific applications.

\section{Impact of Droplet Properties on Emulsion Functionality}

The functional performance of an oil-in-water emulsion is strongly dependent on the nature of the oil droplets it contains [6,12-16]. In this section, a brief overview of the relationship between droplet properties and emulsion performance is given, as this information is useful for understanding the reason for utilizing post-homogenization methods to modulate emulsion functionality.

\subsection{Droplet Concentration}

The concentration of the droplets in an emulsion has a major impact on many of its properties. The viscosity of an oil-in-water emulsion increases as the oil droplet concentration increases due to greater energy dissipation associated with friction [12]. At sufficiently high droplet concentrations an emulsion gains some solid-like characteristics due to close packing (jamming) of the oil droplets together [17]. The lightness of an emulsion tends to increase as the droplet concentration increases due to greater light scattering [14]. The stability of an emulsion to creaming or sedimentation tends to improve as the droplet concentration increases since the movement of the droplets due 
to gravitational forces is hindered by their neighbors $[15,18,19]$. On the other hand, the stability of an emulsion to flocculation and coalescence may decrease with increasing droplet concentration since the frequency and duration of droplet-droplet encounters increases [20]. The perception of creaminess of an emulsion tends to increase with increasing oil droplet concentration, which is important for many emulsion-based foods $[13,21]$.

\subsection{Droplet Size}

The dimensions of the droplets in an oil-in-water emulsion also have a pronounced impact on its properties. The optical properties of emulsions are largely determined by the light scattering efficiency of the droplets, which depends on their size relative to the wavelength of light [14]. When the droplets are much smaller than the wavelength of light $(d<50 \mathrm{~nm})$, they only scatter light waves weakly and therefore appear transparent or only slightly turbid. When the droplets have dimensions similar to the wavelength of light $(d=100 \mathrm{~nm}$ to $10 \mu \mathrm{m})$, then they scatter light waves strongly and the emulsion appears highly turbid or opaque. When the droplets are much larger than the wavelength of light $(d>50 \mu \mathrm{m})$, then they again scatter light weakly and the system appears less turbid or opaque. The droplet size also plays a critical role in determining the long-term stability of emulsions. The rate of droplet flocculation, coalescence, and gravitational separation tends to decrease with decreasing droplet size [20,22,23], whereas the rate of Ostwald ripening tends to increase [24]. Droplet size may also impact the rheological properties of emulsions by altering their effective volume, particularly when the thickness of the interfacial layer is on a similar length scale as the dimensions of the oily core $[22,23]$. The release rate of encapsulated substances within emulsion droplets tends to increase as the droplet size decreases because the diffusion pathway decreases [25].

\subsection{Droplet Charge and Other Interfacial Properties}

The thin layer of emulsifier molecules that coats the oil droplets in an oil-in-water emulsion also has a pronounced influence on its functional attributes [26]. The charge, thickness, packing, and chemical reactivity of the interfacial layer can be controlled by selecting appropriate emulsifiers and solution conditions (such as $\mathrm{pH}$, ionic strength, and temperature). Interfacial properties have a major impact on the physical stability of emulsions [22]. For example, the strength of the electrostatic repulsion between oil droplets tends to increase as their electrical potential increases, whereas the strength of the steric repulsion increases as the thickness of the interfacial layer increases. The rate of Ostwald ripening depends on the interfacial tension and rheology [27]. Interfacial properties may also have an impact on the chemical stability of the oil phase [28], as well as the release of any encapsulated substances [25]. Control of the interfacial properties is therefore essential for ensuring good emulsion stability and functional performance.

\subsection{Disperse Phase Composition}

Oil-in-water emulsions can be prepared using a variety of different oils (which may be pure substances or mixtures), which provides some flexibility over the disperse phase composition. Oils with different densities, viscosities, interfacial tensions, polarities, solvent properties, and nutritional attributes can be utilized depending on the application. Many of these oil phase characteristics influence the ability to form small droplets in emulsions during homogenization, as well as the ability to create emulsions that remain stable after homogenization [6]. Disperse phase composition may also alter the chemical stability of emulsions (e.g., to lipid oxidation) [29] or their gastrointestinal fate (e.g., the rate and extent of digestion) [30].

\subsection{Physical State}

The droplets in an oil-in-water emulsion are usually liquid, since it is necessary that both the oil and water phases be in a fluid state during the homogenization process [31]. Nevertheless, it is possible for the oil phase to crystallize and form solid particles under certain conditions. The physical 
state of the oil droplets may influence the functional performance of the droplets in a number of ways. Firstly, the density of the oil droplets typically increases, which will alter the susceptibility to creaming and sedimentation [6]. Secondly, the refractive index of the oil droplets typically increases, which will increase the degree of light scattering in the system [32]. Thirdly, the rate of any molecular diffusion processes inside the oil phase will tend to be reduced when the lipid phase becomes solid, which may be useful for inhibiting undesirable chemical reactions or inhibiting release of encapsulated bioactive molecules $[25,33]$.

\subsection{Local Environment}

The local environment of the oil droplets within an emulsion may alter their functional attributes. The aqueous phase surrounding the oil droplets may vary in its composition or structure, which can alter the chemical stability of any components trapped within the oil droplets.

\subsection{Droplet Spatial Distribution}

The droplets in an emulsion may vary in their aggregation state. They may exist as isolated droplets or they may be present in clusters (flocs) that are associated with each other. The characteristics of the flocs formed depend on the number of droplets present, the strength of the droplet-droplet interactions, and the organization of the droplets within the flocs (compact or open). An emulsion containing flocculated droplets behaves very differently from one containing isolated droplets. For example, a flocculated emulsion tends to have a much higher viscosity than a non-flocculated emulsion at the same oil content [18]. In addition, the droplets in a dilute emulsion tend to cream more rapidly when they are flocculated due to the increase in particle size. However, the droplets in a concentrated emulsion may cream more slowly when they are flocculated because a three-dimensional particle network is formed that restricts droplet movement.

\section{Post-Homogenization Droplet Modification Methods}

Many of the properties of the droplets in an oil-in-water emulsion can be altered after the emulsion has been formed. Some of the most important methods to achieve this goal are highlighted below and illustrated in Figure 1.

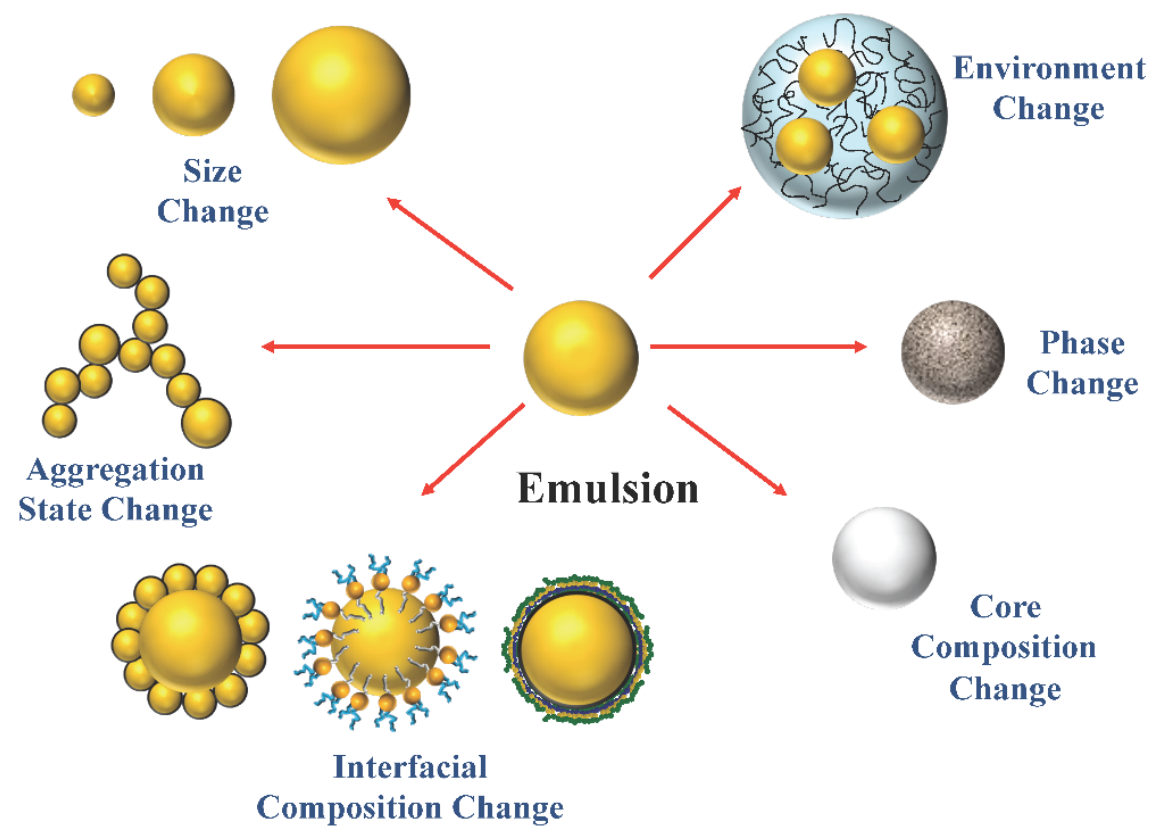

Figure 1. The droplets in an oil-in-water emulsion may be changed using post-homogenization techniques. 


\subsection{Droplet Concentration: Dilution and Concentration Methods}

One of the simplest properties of an emulsion that can be modified after homogenization is the droplet concentration [6]. For example, one could produce a relatively concentrated oil-in-water emulsion by homogenization so as to reduce energy costs, and then dilute it afterwards by adding aqueous phase. Alternatively, the concentration of the droplets in an emulsion could be increased by removing some of the aqueous phase by evaporation or ultrafiltration. Indeed, one can convert an oil-in-water emulsion into a powdered form by removing most of the water using spray drying or freeze drying methods [34,35]. The emulsion can then be reconstituted by adding the powder to water and stirring. For commercial applications, removal of some of the water from an emulsion is often carried out to reduce transport and storage costs, to increase shelf life, and to improve the ease of use of emulsions [36]. Emulsion-based ingredients (such as colors, flavors, vitamins, and nutraceuticals) are often sold in a concentrated form that is then diluted into the final product.

\subsection{Droplet Size: Disperse Phase Evaporation and Ripening Methods}

After homogenization, an oil-in-water emulsion typically has a certain particle size distribution that is determined by product formulation and homogenization conditions [6]. Nevertheless, the particle size distribution can be altered after homogenization using a number of approaches. This may be done to alter the optical properties, rheology, stability, or gastrointestinal fate of an emulsion. For example, in some commercial applications it is important to have emulsion-based products that are optically transparent (such as fortified waters and soft drinks) and so the droplets must be small enough that they do not scatter light strongly [6,14]. The stability of emulsions to creaming and gravitational separation can be improved by reducing the droplet size, which may lead to increases in product shelf life [22]. In pharmaceutical and nutraceutical applications it has been shown that the bioavailability of encapsulated components often increases as the particle size of the delivery system decreases [37]. Consequently, if sufficiently small droplets cannot be achieved using a conventional homogenization approach, it may be necessary to reduce the size further using a post-homogenization method. A number of methods are available to change the droplet size after an emulsion has been prepared.

Disperse Phase Evaporation/Dissolution: An oil-in-water emulsion is typically fabricated by homogenizing an organic phase with an aqueous phase. The size of the droplets within an emulsion can be reduced after it has been formed if one of the components in the organic phase is volatile [38]. For example, the organic phase may contain a non-volatile component (such as a triglyceride) and a volatile component (such as hexane). After homogenization, the emulsion is heated to drive off the volatile component, which causes the oil droplets to shrink in size (Figure 2). An estimate of the change in droplet size due to this process can be obtained using the following equation:

$$
d_{F}=d_{I} \sqrt[3]{\theta}
$$

Here, $d_{\mathrm{I}}$ and $d_{\mathrm{F}}$ are the initial and final diameters of the droplets before and after evaporation, and $\theta$ is the initial volume fraction of the non-volatile component within the organic phase before evaporation. Thus, the overall diameter of the oil droplets decreases as the concentration of the non-volatile component in the initial organic phase decreases. The main drawback of this method is that the droplet size scales with the cube-root of the non-volatile component concentration. Thus, to reduce the diameter of the droplets by half, one would need to decrease the concentration of non-volatile component by one eighth. In other words, the organic phase would have to contain about $12.5 \%$ non-volatile component, and $87.5 \%$ volatile component to reduce the droplet size by $50 \%$.

A similar approach can be used if one of the organic components is partially miscible with the aqueous phase [38]. An oil-in-water emulsion can be produced by homogenizing an organic phase with an aqueous phase that is saturated with the partially miscible organic component. Then the emulsion is diluted with water, which will cause some of the partially miscible component to diffuse out of the droplets and into the surrounding water. 


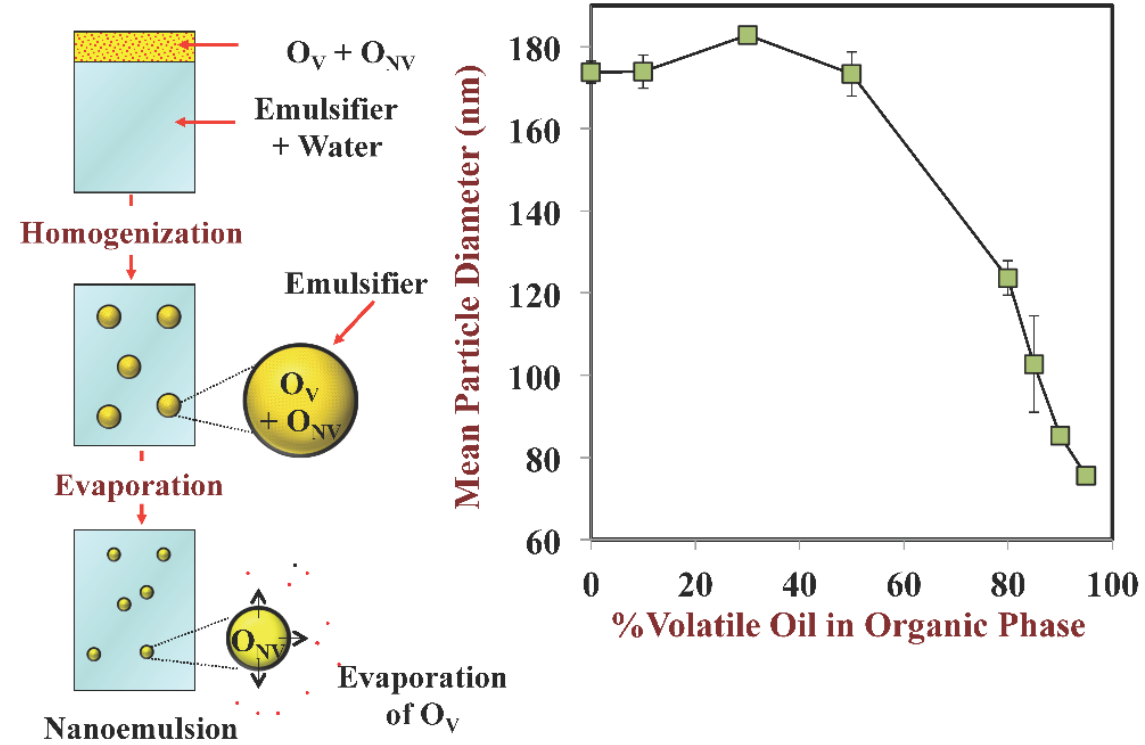

Figure 2. The droplets in an oil-in-water emulsion may be reduced in size after homogenization by evaporation methods. A volatile oil $\left(\mathrm{O}_{\mathrm{V}}\right)$ and non-volatile oil $\left(\mathrm{O}_{\mathrm{NV}}\right)$ are homogenized to form an emulsion, and then the volatile oil is removed by evaporation [38].

The above approaches have been used to produce protein-coated lipid nanoparticles [39,40]. Initially, a protein-stabilized oil-in-water emulsion was formed by homogenization using a mixture of non-volatile oil (corn oil) and volatile oil (ethyl acetate or hexane) as the oil phase. After formation, the volatile oil was removed from the oil phase by evaporation, which caused the oil droplets to shrink into the nanometer range. As a result, the turbidity of the system decreased appreciably because the smaller droplets scattered light less efficiently. The nanoemulsions formed using this solvent evaporation method were shown to have improved physical stability to droplet aggregation and creaming, which was attributed to the relatively small size of the droplets they contained [38]. Conversely, lipid oxidation was faster in the nanoemulsions than conventional emulsions, which was attributed to their relatively high surface area.

Controlled Ripening: The droplet size distribution of an emulsion may be altered by Ostwald ripening processes if the oil phase has an appreciable solubility within the aqueous phase $[24,41]$. In this case, some of the oil molecules diffuse through the aqueous phase from the smaller droplets to the larger droplets (Figure 3). Eventually, this process should lead to a specific monomodal particle size distribution being formed (for a single oil type), which may be advantageous for some applications. However, the particles would continue to grow throughout storage, which may be undesirable. Droplet growth due to Ostwald ripening may be inhibited by crystallizing the droplets after a certain time (see later), or by using a mixture of different oils within the droplets [42]. Typically, one uses an organic phase that contains one component that has a very low solubility in water $\left(O_{\mathrm{L}}\right)$ and another component that has a relatively high solubility in water $\left(\mathrm{O}_{\mathrm{H}}\right)$. It should be noted that the term "relatively high" typically means that the oil phase has a fraction of a percent solubility in water. In an emulsion that contains a mixture of $O_{\mathrm{H}}$ and $O_{\mathrm{L}}$ in the organic phase, the $O_{\mathrm{H}}$ molecules will rapidly diffuse from the small to large droplets, but the $O_{\mathrm{L}}$ molecules will remain trapped in their original droplets. Consequently, there will be an increase in $O_{\mathrm{L}}$ concentration in the smaller droplets, and a decrease in $O_{\mathrm{L}}$ concentration in the larger droplets. This concentration gradient is thermodynamically unfavorable because of entropy of mixing effects, and will therefore oppose further droplet growth due to Ostwald ripening. By careful selection of the initial oil phase composition it may therefore be possible to control the nature of the particle size distribution by controlling droplet growth after homogenization. 


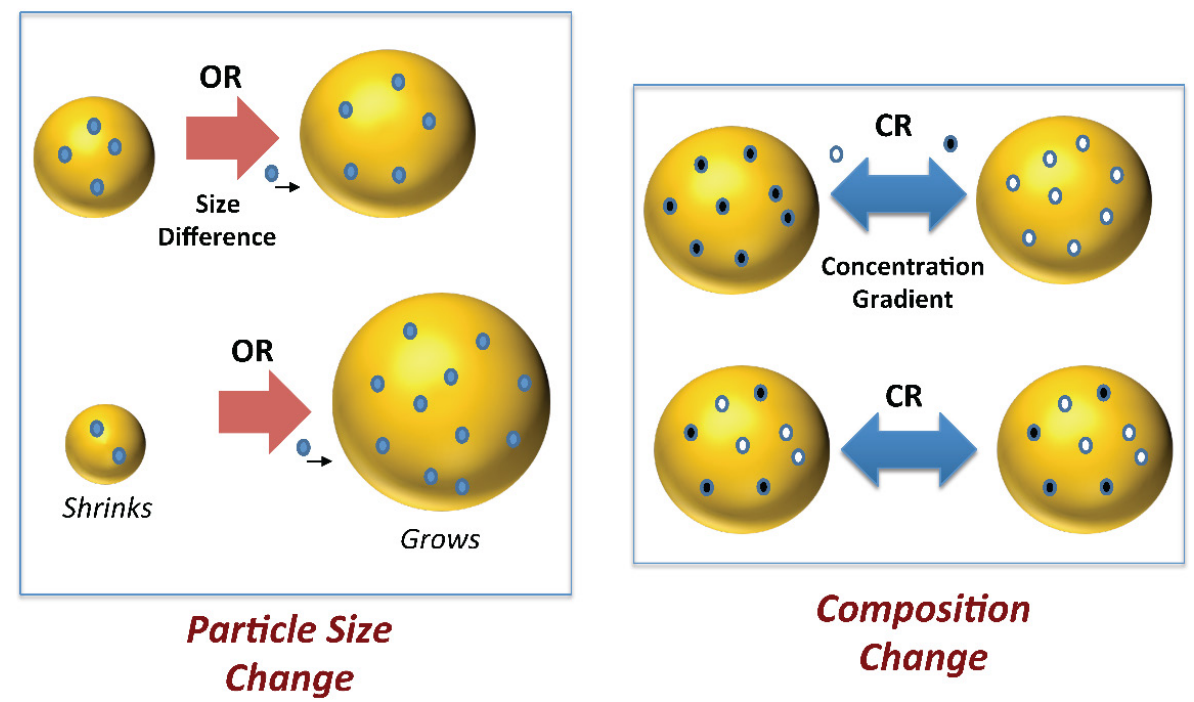

Figure 3. The particle size distribution and/or composition of the droplets in an oil-in-water emulsion may be altered after homogenization using Ostwald ripening (OR) or compositional ripening (CR) processes. In both cases, oil phase molecules diffuse through the aqueous phase.

An alternative approach for altering the particle size distribution is to mix two emulsions together with different droplet sizes and/or compositions. As a consequence, the droplet size distribution may change due to a combination of Ostwald or compositional ripening effects [43].

\subsection{Droplet Charge and other Interfacial Properties: Surfactant Exchange and Coating Methods}

Certain types of emulsifiers are highly effective at producing small droplets during homogenization, but are not particularly effective at stabilizing the droplets formed against environmental stresses. Conversely, other types of emulsifiers are highly effective at producing droplets that are resistant to environmental stresses, but they are not particularly effective at producing small droplets during homogenization. Consequently, in some situations it may be better to utilize one type of emulsifier to form an emulsion containing small droplets, and then to alter the interfacial properties afterwards. In addition, it may be desirable to change the interfacial properties of an emulsifier after homogenization to tailor its properties, e.g., to create droplets with different electrical characteristics. For example, the physical stability of emulsions in commercial products is strongly dependent on the magnitude of the droplet charge, and how it changes with $\mathrm{pH}$ and ion addition, since this effects the attractive and repulsive colloidal interactions operating between the droplets [6]. The chemical stability of emulsions also depends on their droplet charge, e.g., it has been shown that emulsified unsaturated lipids oxidize more quickly when the droplets are negatively charged because they attract positively charged transition metals that catalyze oxidation to their surfaces [44]. Hence it may be desirable to alter the electrical characteristics of the emulsion droplets after they have been formed.

Alterations in interfacial composition and properties after homogenization can be achieved using a number of approaches.

Surfactant Exchange: An oil-in-water emulsion can be formed using a certain type of emulsifier during homogenization, and then a different kind of emulsifier can be added to the system after homogenization. This second type of emulsifier will compete for the oil-water interface, and may fully or partially displace the first type of emulsifier from the droplet surfaces (Figure 4). To a first approximation, the displacement of one surfactant by another can be described by the following equations, which are based on the Langmuir adsorption isotherm [45]:

$$
\frac{\Gamma_{1}}{\Gamma_{T O T}}=\frac{c_{1} / c_{1,1 / 2}}{c_{1} / c_{1,1 / 2}+c_{2} / c_{2,1 / 2}}
$$




$$
\frac{\Gamma_{2}}{\Gamma_{T O T}}=\frac{c_{2} / c_{2,1 / 2}}{c_{1} / c_{1,1 / 2}+c_{2} / c_{2,1 / 2}}
$$

Here, $c_{1}$ and $c_{2}$ are the aqueous phase concentrations of the two emulsifiers, $\Gamma_{1}$ and $\Gamma_{2}$ are the surface excess concentrations of the emulsifiers at the interface, $\Gamma_{1, T O T \infty}$ and $\Gamma_{2, T O T \infty}$ are the surface excess concentrations at saturation, and $c_{1,1 / 2}$ and $c_{2,1 / 2}$ are the emulsifier concentrations where $\Gamma_{1} / \Gamma_{1, \text { TOT }}$ and $\Gamma_{2} / \Gamma_{2, \text { TOT }}=1 / 2$. The reciprocal of $c_{1 / 2}$ can be taken to be a measure of the surface activity of the emulsifiers, i.e., as $1 / c_{1 / 2}$ increases, the affinity of the emulsifier for the interface increases. These equations assume that all the molecules in the system (solvent and solute) have similar dimensions, and the system is at equilibrium. These equations indicate that the interfacial composition depends on the relative concentrations of the two emulsifiers, as well as their relative affinities for the interface $\left(1 / c_{1 / 2}\right)$.
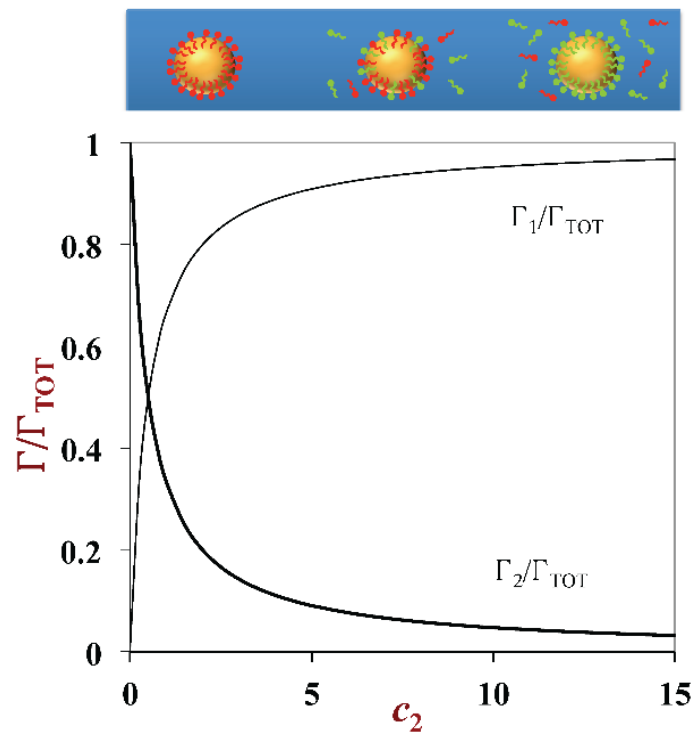

Figure 4. The interfacial composition of the droplets in an oil-in-water emulsion may be altered after homogenization by surfactant displacement methods.

An example of how these equations can be used to estimate alterations in interfacial composition when a more surface-active emulsifier $\left(1 / c_{1 / 2}=1\right)$ is added to a solution containing a fixed concentration of a less surface-active emulsifier $\left(1 / c_{1 / 2}=4\right)$ is shown in Figure 4 . Initially, the interface only contains Type 1 emulsifier, but as the amount of Type 2 emulsifier is increased in the bulk solution, some of the Type 1 emulsifier is displaced from the interface.

The surfactant exchange approach has been used to improve the stability of emulsions formed using low energy methods, such as the phase inversion temperature or spontaneous emulsification methods [46,47]. In these cases, the formation of an emulsion is often facilitated using a non-ionic surfactant that facilitates the spontaneous generation of small oil droplets when the system composition or temperature is changed. However, these surfactants often lead to the formation of emulsions that are highly unstable to coalescence, particularly at elevated temperatures. The stability of the emulsions can be improved after formation by displacing the original surfactant from the droplet surfaces using another surfactant. This approach was used to improve the thermal stability of phase inversion temperature (PIT) nanoemulsions [46]. The nanoemulsions were formed from hydrocarbon oil (tetradecane), non-ionic surfactant (Brij 30), and water using the phase inversion temperature method. A mixture of the surfactant, oil, and water were rapidly cooled from above to below the PIT to spontaneously form a nanoemulsion. However, these nanoemulsions were highly prone to droplet coalescence when the temperature was relatively close to the PIT. The thermal stability of these emulsions was improved by adding another non-ionic surfactant (Tween 20) or 
an anionic surfactant (SDS) after their formation to increase the PIT or to increase the repulsive colloidal interactions. A similar approach has been used to stabilize nanoemulsions formed using the spontaneous emulsification method [47].

Surfactant exchange has also been used to alter the electrical charge on emulsion droplets after homogenization [48]. Emulsions containing oil droplets with a low net charge were prepared by homogenizing oil and water together in the presence of a non-ionic surfactant (Tween 80), and then the charge was altered by adding either cationic (lauric arginate) or anionic (sodium dodecyl sulfate) surfactants to the system. A range of droplet charges from highly positive to highly negative could be created using this approach.

Interfacial Deposition: Another means of altering the characteristics of the droplet interface after the formation of an emulsion is to use interfacial deposition methods $[5,49,50]$. These methods involve depositing a substance onto the surfaces of the oil droplets using some form of attractive force. The most commonly used attractive force is electrostatic attraction between a charged substance and an oppositely charged droplet, but other attractive forces could also be used, such as hydrophobic attraction or hydrogen bond formation. The substances that are deposited onto the surface of an emulsion droplet may be biopolymers (such as proteins or polysaccharides) or colloidal particles (such as silica, titanium dioxide, or chitin nanoparticles). By far the most commonly used interfacial deposition method has been layer-by-layer ( $\mathrm{LbL}$ ) electrostatic deposition of charged biopolymers onto oppositely charged oil droplets [50]. Typically, a primary emulsion is made using an electrically charged emulsifier (such as an ionic surfactant or protein), and then the emulsion is mixed with a solution containing oppositely charged biopolymer molecules (proteins or polysaccharides). Under appropriate conditions, this leads to the formation of oil droplets coated by a surfactant-biopolymer layer (Figure 5). This process can be repeated a number of times using a series of biopolymer solutions with alternating charge characteristics, e.g., cationic, then anionic, then cationic etc. One must be careful to control the biopolymer and droplet concentrations during this process to avoid depletion or bridging flocculation within the emulsion $[49,51]$. The electrostatic deposition method has also been used to create a coating of charged small oil droplets around oppositely charged large oil droplets [52].

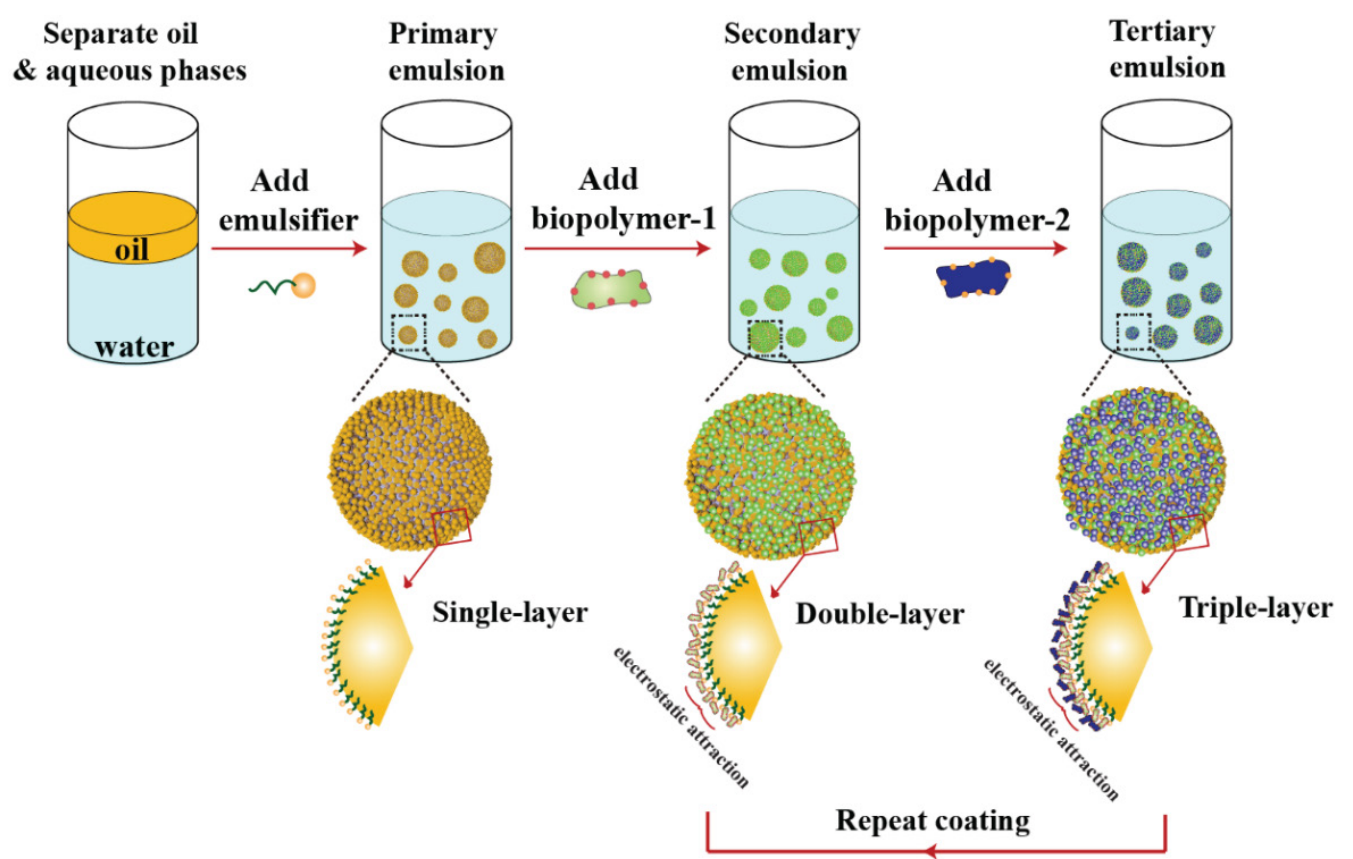

Figure 5. The interfacial composition of the droplets in an oil-in-water emulsion may be altered after homogenization by electrostatic deposition methods. In this case layers of charged biopolymers are deposited onto oppositely charged droplets. 


\subsection{Disperse Phase Composition: Compositional Ripening Methods}

The ability to produce small droplet sizes during the formation of an oil-in-water emulsion depends on oil phase properties, such as viscosity, polarity, and interfacial tension [31]. Consequently, it is often advantageous to utilize a certain type of oil to form an oil-in-water emulsion so as to ensure that small droplets are produced during homogenization. However, it may be desirable to alter the composition of the oil phase after homogenization to modify the stability or functionality of the emulsion. For example, it may be useful to trap an antimicrobial, antioxidant, color, or flavor inside of the oil droplets after the system has been formed. In some situations, it is possible to change the composition of the oil phase after homogenization using compositional ripening methods (Figure 3).

In this case, an emulsion prepared using one kind of oil is mixed with another emulsion prepared using a different kind of oil. If one or both of the oil phases have some solubility in the aqueous phase, then the exchange of oil molecules between droplets will occur through a molecular diffusion process (Figure 3). The final composition of the droplets will depend on the initial sizes and compositions of the droplets in the two emulsions used to form the mixed system. The potential of this approach has been demonstrated using emulsions that were composed of two different types of hydrocarbon oils: hexadecane and octadecane [53,54]. When a hexadecane emulsion is mixed with an octadecane emulsion there is an exchange of oil molecules between the droplets so that the final oil phase composition of all the droplets is similar. As mentioned earlier, this approach may be useful for introducing non-polar components into pre-existing emulsions.

\subsection{Physical State: Controlling Temperature or Solvent Quality}

Oil-in-water emulsions or nanoemulsions produced by both low- and high-energy methods contain lipid particles with a liquid oil phase [22]. Nevertheless, for certain applications it is advantageous to have a solid phase within the lipid particles, e.g., to protect encapsulated components from release or from chemical degradation [55-57]. In particular, there has been considerable interest in the development of solid lipid nanoparticles (SLNs) or nanostructured lipid carriers (NLCs) that contain fully or partially crystalline lipid particles suspended in water for this purpose. The droplets in an oil-in-water emulsion can be made to crystallize by cooling them below the melting point of the lipids present. Consequently, it is important to select lipids that have a melting point that is within the range desired for the specific application. The melting point should be low enough to allow the oil phase to be melted prior to homogenization, but high enough to ensure that the oil droplets can be crystallized after homogenization. In addition, it should be noted that the droplets in an oil-in-water emulsion or nanoemulsion typically have to be cooled considerably below the thermodynamic melting point before any crystallization is observed due to supercooling effects [58]. This is because the chance of finding an impurity that can act as a catalyst for nucleation inside an individual oil droplets is reduced considerably when the droplet size falls below a certain level [59]. Another factor that needs to be considered is the potential shape changes of the lipid droplets that may occur when they crystallize [60]. Lipid particles may retain an approximately spherical shape, or they may undergo appreciably changes in morphology depending on the cooling rate, holding temperature, oil type, and emulsifier type. These changes in particle morphology can lead to drastic changes in the rheology and stability of lipid nanoparticle suspensions [61,62].

\subsection{Environment: Embedding Methods}

The local environment of lipid droplets can be altered by embedding them within larger particles such as biopolymer microparticles or microgels (Figure 1). For commercial applications this may be important because embedding the lipid droplets may improve their chemical stability, modulate their release properties, or alter their gastrointestinal fate. In these cases, it is important to carefully select the dimensions, composition, pore size, and behavior of the biopolymer particles surrounding the lipid droplets. For example, the biopolymer particles may be designed so that they contain antioxidants to 
protect chemically labile substances, or that have dimensions and pore sizes that effectively inhibit the molecular diffusion of active ingredients until they reach the required site of action.

Embedding is typically achieved by mixing an oil-in-water emulsion with a solution of biopolymers, and then altering system conditions (such as composition or temperature) to promote aggregation or cross-linking of the biopolymer molecules [63-66]. The most commonly used biopolymers for this process are proteins and polysaccharides. A variety of different types of biopolymer particles can be formed by using different biopolymers, cross-linking methods, and preparation methods. Some of the most commonly used embedding methods are briefly highlighted below.

Injection Methods: Injection methods involve injecting a mixture of oil droplets and biopolymer molecules into a solution that promotes biopolymer cross-linking and gelation [66]. The nature of the cross-linking method used depends on the type of biopolymer used: anionic alginate, pectin, or carrageenan can be cross-linked by cationic mineral ions (such as calcium); gelatin can be cross-linked by cooling to induce hydrogen bond formation between helical regions; whey proteins can be cross-linked by heating to promote protein unfolding and aggregation through hydrophobic bonds.

This method has been used to create oil droplets embedded within hydrogel particles consisting of various types of biopolymers. Oil droplets have been mixed with an aqueous solution of alginate molecules and then injected into a calcium solution $[67,68]$. When the anionic alginate molecules come into contact with the calcium solution they are cross-linked due to salt bridge formation by the cationic calcium ions. As a result, approximately spherical biopolymer particles are formed that contain the oil droplets inside. Studies have shown that oil droplets trapped in this type of biopolymer particle are more stable to lipid oxidation [69-71], and that the rate of lipid digestion under simulated gastrointestinal conditions is reduced [67,72]. This latter property may be useful for developing delivery systems for lipophilic bioactive components intended for release in the colon.

Oil droplets have also been successfully embedded into gelatin-based hydrogel particles [73]. A mixture of oil droplets and an aqueous solution containing gelatin molecules was gelled through a combination of cooling (to promote cross-linking of helical regions through hydrogen bonds) and genipin addition (to form covalent cross-links). This study showed that the pore size of the gelatin network altered the release kinetics of the oil droplets, which may be useful for designing delivery systems for pharmaceutical and nutraceutical applications.

Antisolvent Precipitation Methods: These methods involve mixing the oil droplets and biopolymer together in a certain solvent, and then injecting them into an antisolvent for the biopolymer molecules [64,74]. When exposed to the antisolvent the biopolymers tend to associate with each other and form particles that trap the lipid droplets inside. For a hydrophobic biopolymer, the solvent would be an organic liquid while the antisolvent would be water. Conversely, for a hydrophilic biopolymer the solvent would typically be water and the antisolvent would be an organic liquid. The biopolymer particles formed often have to be stabilized against aggregation by adding an emulsifier to the antisolvent [75].

Nutraceutical-loaded oil droplets have been successfully incorporated into modified starch particles using the antisolvent precipitation method [76]. In this study, oil-soluble $\beta$-carotene was dissolved in a hot, pressured organic liquid (solvent phase), which was then injected into a cold aqueous modified starch solution (antisolvent phase). When the $\beta$-carotene solution came into contact with the aqueous modified starch solution the $\beta$-carotene rapidly precipitated due to the reduction in solvent quality and temperature. The residual of organic solvent could then be removed by vacuum evaporation to obtain an aqueous dispersion of $\beta$-carotene particles protected by modified starch. Another related study showed that the encapsulation efficiency of $\beta$-carotene using this approach could be increased to $70 \%-80 \%$ [77].

Electrostatic Complexation Methods: These methods involve mixing a solution that contains oil droplets and a charged biopolymer with another solution that contains an oppositely charged biopolymer [64]. Alternatively, the oil droplets and two biopolymers can be mixed together under $\mathrm{pH}$ conditions where they all have similar charges, and then the $\mathrm{pH}$ can be adjusted so 
that the two biopolymers have opposite charges. The two oppositely charged biopolymers then associate with each other through electrostatic attraction thereby trapping the oil droplets inside. Typically, coacervation is carried out using a protein and an ionic polysaccharide, since the charge on the protein can be moved from positive to negative by increasing the $\mathrm{pH}$ from low to high The hydrogel particles formed may be cross-linked after production to improve their stability and functional attributes, e.g., using physical, chemical, or enzymatic methods.

Oil droplets have recently been embedded in electrostatic complexes formed by mixing cationic gelatin and anionic pectin molecules together at $\mathrm{pH} 5.5$ [78]. The oil droplets could be released from the hydrogel beads by heating, which led to a helix-coil transition of the gelatin molecules. These systems may therefore be useful as a temperature-triggered release system for hydrophobic active molecules. In another study, oil droplets were embedded in electrostatic complexes formed by mixing caseinate and alginate together [79]. These complexes remained intact at $\mathrm{pH}$ values from 4 to 5 , but dissociated when the $\mathrm{pH}$ was increased to high values. Consequently, these systems could be used as $\mathrm{pH}$-triggered release systems for hydrophobic bioactives. Oil droplets have also been encapsulated within electrostatic complexes formed from fish gelatin and gum arabic [80].

Furthermore, oil droplets have been successfully incorporated into protein-protein multilayer electrostatic complexes formed by mixing anionic whey protein isolate and cationic fish gelatin under appropriate $\mathrm{pH}$ conditions [81]. This study showed that the physical and chemical stability of the emulsions formed depended on the properties of the multilayer complexes. Therefore, the design of multilayer emulsions with specific layer compositions and structures could be used in the development of emulsion-based delivery systems with improved functional properties.

Thermodynamic Incompatibility Methods: These methods involve mixing oil droplets with a solution that contains two biopolymers that repel each other. At sufficiently high concentrations the solution separates into two phases: one phase rich in one biopolymer and depleted in the other, while the opposite is true in the other phase. This phase separated system can then be blended to form a "water-in-water" emulsion. Under certain conditions the oil droplets preferentially partition into the aqueous phase that makes up the dispersed phase. The inner aqueous phase can then be gelled using an appropriate method (such as a temperature change or addition of a cross-linking agent), which leads to the formation of hydrogel particles with oil droplets trapped inside (Figure 6).

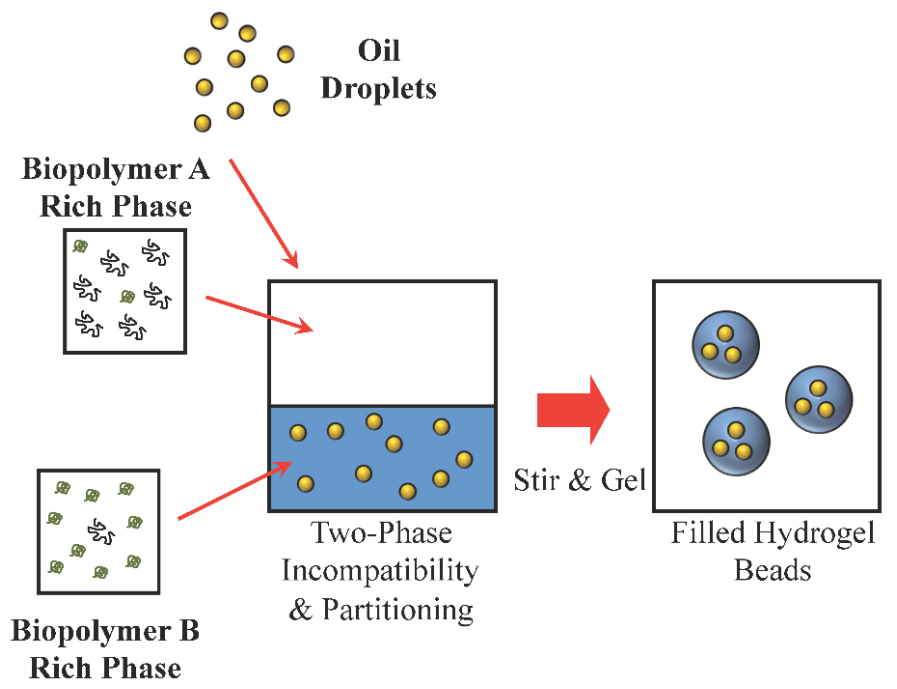

Figure 6. Schematic representation of production of the encapsulation of oil droplets in hydrogel particles formed by thermodynamic incompatibility method. An oil-in-water-in-water $(\mathrm{O} / \mathrm{W} / \mathrm{W})$ emulsion may form when lipid droplets and two biopolymers are mixed together under conditions where phase separation occurs. 
This method has been used to encapsulate lipid droplets within hydrogel particles consisting of protein (caseinate) and polysaccharides (pectin) [82]. The oil droplets, caseinate, and pectin were mixed together at neutral $\mathrm{pH}$ promoting separation into one phase that is rich in caseinate and another phase that is rich in pectin. When this system was sheared a water-in-water emulsion was formed that consisted of droplets of the caseinate-rich phase dispersed within the pectin-rich phase. The oil droplets were found to preferentially partition into the caseinate-rich phase, which was attributed to as osmotic pressure effect. The inner aqueous phase was then gelled by adding calcium ions, and stabilized by reducing the $\mathrm{pH}$ to induce adsorption of a layer of pectin molecules around the caseinate-rich droplets. It was shown that the oil droplets within the hydrogel beads could be protected from lipid oxidation [70], but that they would still be released under simulated gastrointestinal conditions [83], which is important for the development of effective encapsulation systems. Phase separation of gelatin-starch systems has also been utilized to produce filled hydrogel beads based on the thermodynamic incompatibility mechanism [84].

\subsection{Droplet Spatial Distribution: Controlled Droplet Aggregation}

Finally, the functional performance of oil-in-water emulsions can be tailored after formation by controlling the aggregation state of the droplets. Changing the aggregation state of the droplets may be desirable to control the rheological properties of the final emulsion. For example, emulsions containing flocculated droplets typically have much higher viscosities than non-flocculated ones, which may be useful for creating products with viscous, paste-like, or solid-like properties. The droplets can be made to aggregate with each other by adjusting system conditions so that the attractive interactions acting between the droplets overcome the repulsive interactions $[6,85]$. The method used to induce flocculation is highly system dependent, and in particular on the nature of the droplet interface. Flocculation may be induced by increasing attractive interactions, such as electrostatic, depletion, hydrophobic or bridging attraction, or by reducing repulsive interactions such as electrostatic or steric repulsion. The strength and range of the overall colloidal interactions between the droplets determines the nature of the flocs formed, such as their size, morphology, and integrity.

An example of this approach is the controlled electrostatic heteroaggregation of the droplets in oil-in-water emulsions [86-88]. Heteroaggregation is induced by mixing an emulsion containing positively charged droplets with another emulsion containing negatively charged droplets (Figure 7). The flocculated emulsions formed had a high viscosity or paste-like texture, whereas the two initial emulsions had relatively low viscosities. These types of flocculated emulsions may therefore be useful for forming reduced calorie products, or for creating novel textural attributes.

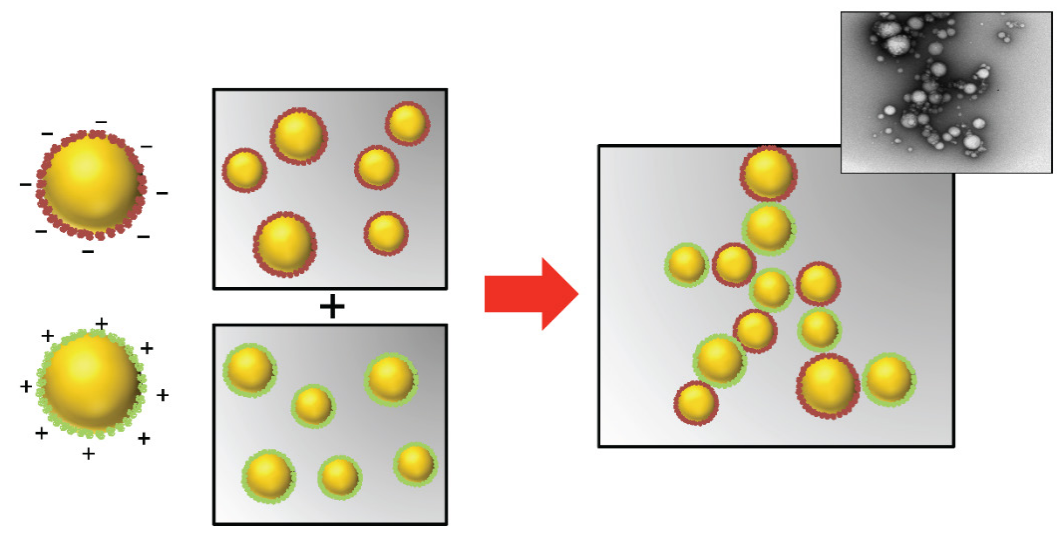

Figure 7. The physicochemical and functional properties of oil-in-water emulsions may be altered after homogenization by using controlled droplet aggregation methods. In this case oppositely charged droplets are made to aggregate through electrostatic attraction. The inset shows an electron microscopy image. 


\section{Conclusions}

The stability, physicochemical properties and functional performance of oil-in-water emulsions are usually controlled by manipulating the ingredients and/or homogenization methods used to fabricate them. Nevertheless, there are a number of different post-homogenization techniques that can be used to alter the properties of oil droplets after they have been formed. The concentration, size, composition, physical state, charge, or aggregation state of the droplets can be altered using these techniques, which allows one to tailor emulsion properties for specific applications. The utilization of these post-homogenization techniques in combination with traditional homogenization techniques provides scientists and manufacturers considerable scope in manipulating emulsion properties. For example, manufacturers may be able to create products with novel or improved optical, rheological, stability, or gastrointestinal properties.

Acknowledgments: This material was partly based upon work supported by the Cooperative State Research, Extension, Education Service, USDA, Massachusetts Agricultural Experiment Station (MAS00491) and USDA, NRI Grants (2013-03795, and 2014-67021). Long Bai would like to thank the Chinese Scholarship Council for support.

Author Contributions: David Julian McClements planned and wrote the initial draft of the manuscript and the figures. Long Bai contributed additional material to a number of sections.

Conflicts of Interest: The authors declare no conflict of interest.

\section{References}

1. Donsi, F.; Sessa, M.; Mediouni, H.; Mgaidi, A.; Ferrari, G. Encapsulation of bioactive compounds in nanoemulsion-based delivery systems. In Proceedings of the 11th International Congress on Engineering and Food, Athens, Greece, 22-26 May 2011; Saravacos, G., Taoukis, P., Krokida, M., Karathanos, V., Lazarides, H., Stoforos, N., Tzia, C., Yanniotis, S., Eds.; Volume 1, pp. 1666-1671.

2. McClements, D.J. Crystals and crystallization in oil-in-water emulsions: Implications for emulsion-based delivery systems. Adv. Colloid Interface Sci. 2012, 174, 1-30. [CrossRef] [PubMed]

3. Silva, H.D.; Cerqueira, M.A.; Vicente, A.A. Nanoemulsions for food applications: Development and characterization. Food Bioprocess Technol. 2012, 5, 854-867. [CrossRef]

4. Velikov, K.P.; Pelan, E. Colloidal delivery systems for micronutrients and nutraceuticals. Soft Matter 2008, 4, 1964-1980. [CrossRef]

5. McClements, D.J. Advances in fabrication of emulsions with enhanced functionality using structural design principles. Curr. Opin. Colloid Interface Sci. 2012, 17, 235-245. [CrossRef]

6. McClements, D.J. Food Emulsions: Principles, Practice and Techniques, 3rd ed.; CRC Press: Boca Raton, FL, USA, 2015.

7. Maindarkar, S.N.; Hoogland, H.; Henson, M.A. Predicting the combined effects of oil and surfactant concentrations on the drop size distributions of homogenized emulsions. Colloids Surfaces A Physicochem. Eng. Asp. 2015, 467, 18-30. [CrossRef]

8. Raikar, N.B.; Bhatia, S.R.; Malone, M.F.; Henson, M.A. Experimental studies and population balance equation models for breakage prediction of emulsion drop size distributions. Chem. Eng. Sci. 2009, 64, 2433-2447. [CrossRef]

9. Hakansson, A.; Innings, F.; Tragardh, C.; Bergenstahl, B. A high-pressure homogenization emulsification model-improved emulsifier transport and hydrodynamic coupling. Chem. Eng. Sci. 2013, 91, 44-53. [CrossRef]

10. Galooyak, S.S.; Dabir, B.; Zolfaghari, M. An innovative numerical approach for simulation of emulsion formation in a microfluidizer. Colloids Surfaces A Physicochem. Eng. Asp. 2015, 487, 169-179. [CrossRef]

11. Bai, L.; McClements, D.J. Development of microfluidization methods for efficient production of concentrated nanoemulsions: Comparison of single- and dual-channel microfluidizers. J. Colloid Interface Sci. 2016, 466, 206-212. [CrossRef] [PubMed]

12. Derkach, S.R. Rheology of emulsions. Adv. Colloid Interface Sci. 2009, 151, 1-23. [CrossRef] [PubMed]

13. Le Reverend, B.J.D.; Norton, I.T.; Cox, P.W.; Spyropoulos, F. Colloidal aspects of eating. Curr. Opin. Colloid Interface Sci. 2010, 15, 84-89. [CrossRef] 
14. McClements, D.J. Theoretical prediction of emulsion color. Adv. Colloid Interface Sci. 2002, 97, 63-89. [CrossRef]

15. Robins, M.M. Emulsions-Creaming phenomena. Curr. Opin. Colloid Interface Sci. 2000, 5, $265-272$. [CrossRef]

16. Hiemenz, P.C.; Rajagopalan, R. Principles of Colloid and Surface Chemistry, 3rd ed.; Marcel Dekker: New York, NY, USA, 1997.

17. Pal, R. Rheology of high internal phase ratio emulsions. Food Hydrocoll. 2006, 20, 997-1005. [CrossRef]

18. Chanamai, R.; McClements, D.J. Dependence of creaming and rheology of monodisperse oil-in-water emulsions on droplet size and concentration. Colloids Surfaces A Physicochem. Eng. Asp. 2000, 172, 79-86. [CrossRef]

19. Sek, J.; Jozwiak, B. Application of the continuity theory for the prediction of creaming phenomena in emulsions. J. Dispers. Sci. Technol. 2015, 36, 991-999. [CrossRef]

20. Rahn-Chique, K.; Urbina-Villalba, G. Use of the lifshitz-slyosov-wagner theory for the prediction of the drop size of an emulsion subject to flocculation and coalescence. Interciencia 2015, 40, 847-853.

21. Van Aken, G.A.; Vingerhoeds, M.H.; de Wijk, R.A. Textural perception of liquid emulsions: Role of oil content, oil viscosity and emulsion viscosity. Food Hydrocoll. 2011, 25, 789-796. [CrossRef]

22. McClements, D.J. Edible nanoemulsions: Fabrication, properties, and functional performance. Soft Matter 2011, 7, 2297-2316. [CrossRef]

23. McClements, D.J.; Rao, J. Food-grade nanoemulsions: Formulation, fabrication, properties, performance, biological fate, and potential toxicity. Crit. Rev. Food Sci. Nutr. 2011, 51, 285-330. [CrossRef] [PubMed]

24. Taylor, P. Ostwald ripening in emulsions. Adv. Colloid Interface Sci. 1998, 75, 107-163. [CrossRef]

25. Dan, N. Transport and release in nano-carriers for food applications. J. Food Eng. 2016, 175, $136-144$. [CrossRef]

26. Salcedo-Sandoval, L.; Cofrades, S.; Ruiz-Capillas, C.; Matalanis, A.; McClements, D.J.; Decker, E.A.; Jimenez-Colmenero, F. Oxidative stability of n-3 fatty acids encapsulated in filled hydrogel particles and of pork meat systems containing them. Food Chem. 2015, 184, 207-213. [CrossRef] [PubMed]

27. Mun, S.H.; McClements, D.J. Influence of interfacial characteristics on ostwald ripening in hydrocarbon oil-in-water emulsions. Langmuir 2006, 22, 1551-1554. [CrossRef] [PubMed]

28. Berton-Carabin, C.C.; Ropers, M.H.; Genot, C. Lipid oxidation in oil-in-water emulsions: Involvement of the interfacial layer. Compr. Rev. Food Sci. Food Saf. 2014, 13, 945-977. [CrossRef]

29. Boon, C.S.; Xu, Z.; Yue, X.; McClements, D.J.; Weiss, J.; Decker, E.A. Factors affecting lycopene oxidation in oil-in-water emulsions. J. Agric. Food Chem. 2008, 56, 1408-1414. [CrossRef] [PubMed]

30. Qian, C.; Decker, E.A.; Xiao, H.; McClements, D.J. Nanoemulsion delivery systems: Influence of carrier oil on beta-carotene bioaccessibility. Food Chem. 2012, 135, 1440-1447. [CrossRef] [PubMed]

31. Santana, R.C.; Perrechil, F.A.; Cunha, R.L. High- and low-energy emulsifications for food applications: A focus on process parameters. Food Eng. Rev. 2013, 5, 107-122. [CrossRef]

32. Helgason, T.; Salminen, H.; Kristbergsson, K.; McClements, D.J.; Weiss, J. Formation of transparent solid lipid nanoparticles by microfluidization: Influence of lipid physical state on appearance. J. Colloid Interface Sci. 2015, 448, 114-122. [CrossRef] [PubMed]

33. Jenning, V.; Schafer-Korting, M.; Gohla, S. Vitamin a-loaded solid lipid nanoparticles for topical use drug release properties. J. Control. Release 2000, 66, 115-126. [CrossRef]

34. Drusch, S.; Serfert, Y.; Scampicchio, M.; Schmidt-Hansberg, B.; Schwarz, K. Impact of physicochemical characteristics on the oxidative stability of fish oil microencapsulated by spray-drying. J. Agric. Food Chem. 2007, 55, 11044-11051. [CrossRef] [PubMed]

35. Madene, A.; Jacquot, M.; Scher, J.; Desobry, S. Flavour encapsulation and controlled release-A review. Int. J. Food Sci. Technol. 2006, 41, 1-21. [CrossRef]

36. Kaushik, P.; Dowling, K.; Barrow, C.J.; Adhikari, B. Microencapsulation of omega-3 fatty acids: A review of microencapsulation and characterization methods. J. Funct. Foods 2015, 19, 868-881. [CrossRef]

37. Acosta, E. Bioavailability of nanoparticles in nutrient and nutraceutical delivery. Curr. Opin. Colloid Interface Sci. 2009, 14, 3-15. [CrossRef]

38. Lee, S.J.; Choi, S.J.; Li, Y.; Decker, E.A.; McClements, D.J. Protein-stabilized nanoemulsions and emulsions: Comparison of physicochemical stability, lipid oxidation, and lipase digestibility. J. Agric. Food Chem. 2011, 59, 415-427. [CrossRef] [PubMed] 
39. Lee, S.J.; McClements, D.J. Fabrication of protein-stabilized nanoemulsions using a combined homogenization and amphiphilic solvent dissolution/evaporation approach. Food Hydrocoll. 2010, 24, 560-569. [CrossRef]

40. Troncoso, E.; Aguilera, J.M.; McClements, D.J. Influence of particle size on the in vitro digestibility of protein-coated lipid nanoparticles. J. Colloid Interface Sci. 2012, 382, 110-116. [PubMed]

41. Kabalnov, A.S.; Shchukin, E.D. Ostwald ripening theory-Applications to fluorocarbon emulsion stability. Adv. Colloid Interface Sci. 1992, 38, 69-97.

42. Kabalnov, A.S.; Pertzov, A.V.; Shchukin, E.D. Ostwald ripening in 2-component disperse phase systems-Application to emulsion stability. Colloids Surfaces 1987, 24, 19-32. [CrossRef]

43. Pena, A.A.; Miller, C.A. Solubilization rates of oils in surfactant solutions and their relationship to mass transport in emulsions. Adv. Colloid Interface Sci. 2006, 123, 241-257. [CrossRef] [PubMed]

44. Mei, L.Y.; McClements, D.J.; Decker, E.A. Lipid oxidation in emulsions as affected by charge status of antioxidants and emulsion droplets. J. Agric. Food Chem. 1999, 47, 2267-2273. [CrossRef] [PubMed]

45. Razumovsky, L.; Damodaran, S. Incompatibility of mixing of proteins in adsorbed binary protein films at the air-water interface. J. Agric. Food Chem. 2001, 49, 3080-3086. [CrossRef] [PubMed]

46. Rao, J.J.; McClements, D.J. Stabilization of phase inversion temperature nanoemulsions by surfactant displacement. J. Agric. Food Chem. 2010, 58, 7059-7066. [CrossRef] [PubMed]

47. Saberi, A.H.; Fang, Y.; McClements, D.J. Stabilization of vitamin e-enriched nanoemulsions: Influence of post-homogenization cosurfactant addition. J. Agric. Food Chem. 2014, 62, 1625-1633. [CrossRef] [PubMed]

48. Ziani, K.; Chang, Y.H.; McLandsborough, L.; McClements, D.J. Influence of surfactant charge on antimicrobial efficacy of surfactant-stabilized thyme oil nanoemulsions. J. Agric. Food Chem. 2011, 59, 6247-6255. [CrossRef] [PubMed]

49. Guzey, D.; McClements, D.J. Formation, stability and properties of multilayer emulsions for application in the food industry. Adv. Colloid Interface Sci. 2006, 128, 227-248. [CrossRef] [PubMed]

50. McClements, D.J. Design of nano-laminated coatings to control bioavailability of lipophilic food components. J. Food Sci. 2010, 75, R30-R42. [CrossRef] [PubMed]

51. Zeeb, B.; Thongkaew, C.; Weiss, J. Theoretical and practical considerations in electrostatic depositioning of charged polymers. J. Appl. Polym. Sci. 2014, 131. [CrossRef]

52. Gu, Y.S.; Decker, E.A.; McClements, D.J. Formation of colloidosomes by adsorption of small charged oil droplets onto the surface of large oppositely charged oil droplets. Food Hydrocoll. 2007, 21, 516-526. [CrossRef]

53. McClements, D.J.; Dungan, S.R. Factors that affect the rate of oil exchange between oil-in-water emulsion droplets stabilized by a nonionic surfactant-Droplet size, surfactant concentration, and ionic-strength. J. Phys. Chem. 1993, 97, 7304-7308. [CrossRef]

54. McClements, D.J.; Dungan, S.R.; German, J.B.; Kinsella, J.E. Oil exchange between oil-in-water emulsion droplets stabilized with a nonionic surfactant. Food Hydrocoll. 1992, 6, 415-422. [CrossRef]

55. Muller, R.H.; Mader, K.; Gohla, S. Solid lipid nanoparticles (SLN) for controlled drug delivery-A review of the state of the art. Eur. J. Pharm. Biopharm. 2000, 50, 161-177. [CrossRef]

56. Muller, R.H.; Radtke, M.; Wissing, S.A. Solid lipid nanoparticles (SLN) and nanostructured lipid carriers (NLC) in cosmetic and dermatological preparations. Adv. Drug Deliv. Rev. 2002, 54, S131-S155. [CrossRef]

57. Wissing, S.A.; Kayser, O.; Muller, R.H. Solid lipid nanoparticles for parenteral drug delivery. Adv. Drug Deliv. Rev. 2004, 56, 1257-1272. [CrossRef] [PubMed]

58. Clausse, D. Thermal behaviour of emulsions studied by differential scanning calorimetry. J. Therm. Anal. Calorim. 1998, 51, 191-201. [CrossRef]

59. Coupland, J.N. Crystallization in emulsions. Curr. Opin. Colloid Interface Sci. 2002, 7, 445-450. [CrossRef]

60. Denkov, N.; Tcholakova, S.; Lesov, I.; Cholakova, D.; Smoukov, S.K. Self-shaping of oil droplets via the formation of intermediate rotator phases upon cooling. Nature 2015, 528, 392-395. [CrossRef] [PubMed]

61. Helgason, T.; Awad, T.S.; Kristbergsson, K.; McClements, D.J.; Weiss, J. Influence of polymorphic transformations on gelation of tripalmitin solid lipid nanoparticle suspensions. J. Am. Oil Chem. Soc. 2008, 85, 501-511. [CrossRef]

62. Helgason, T.; Awad, T.S.; Kristbergsson, K.; McClements, D.J.; Weiss, J. Effect of surfactant surface coverage on formation of solid lipid nanoparticles (SLN). J. Colloid Interface Sci. 2009, 334, 75-81. [CrossRef] [PubMed] 
63. Matalanis, A.; Jones, O.G.; McClements, D.J. Structured biopolymer-based delivery systems for encapsulation, protection, and release of lipophilic compounds. Food Hydrocoll. 2011, 25, 1865-1880. [CrossRef]

64. Joye, I.J.; McClements, D.J. Biopolymer-based nanoparticles and microparticles: Fabrication, characterization, and application. Curr. Opin. Colloid Interface Sci. 2014, 19, 417-427. [CrossRef]

65. Shewan, H.M.; Stokes, J.R. Review of techniques to manufacture micro-hydrogel particles for the food industry and their applications. J. Food Eng. 2013, 119, 781-792. [CrossRef]

66. Zhang, Z.P.; Zhang, R.J.; Chen, L.; Tong, Q.Y.; McClements, D.J. Designing hydrogel particles for controlled or targeted release of lipophilic bioactive agents in the gastrointestinal tract. Eur. Polym. J. 2015, 72, 698-716. [CrossRef]

67. Li, Y.; Hu, M.; Du, Y.; Xiao, H.; McClements, D.J. Control of lipase digestibility of emulsified lipids by encapsulation within calcium alginate beads. Food Hydrocoll. 2011, 25, 122-130. [CrossRef]

68. Zeeb, B.; Saberi, A.H.; Weiss, J.; McClements, D.J. Retention and release of oil-in-water emulsions from filled hydrogel beads composed of calcium alginate: Impact of emulsifier type and ph. Soft Matter 2015, 11, 2228-2236. [CrossRef] [PubMed]

69. Tello, F.; Falfan-Cortes, R.N.; Martinez-Bustos, F.; da Silva, V.M.; Hubinger, M.D.; Grosso, C. Alginate and pectin-based particles coated with globular proteins: Production, characterization and anti-oxidative properties. Food Hydrocoll. 2015, 43, 670-678. [CrossRef]

70. Matalanis, A.; Decker, E.A.; McClements, D.J. Inhibition of lipid oxidation by encapsulation of emulsion droplets within hydrogel microspheres. Food Chem. 2012, 132, 766-772. [CrossRef]

71. Zhang, Z.P.; Decker, E.A.; McClements, D.J. Encapsulation, protection, and release of polyunsaturated lipids using biopolymer-based hydrogel particles. Food Res. Int. 2014, 64, 520-526. [CrossRef]

72. Li, Y.; Kim, J.; Park, Y.; McClements, D.J. Modulation of lipid digestibility using structured emulsion-based delivery systems: Comparison of in vivo and in vitro measurements. Food Funct. 2012, 3, 528-536. [CrossRef] [PubMed]

73. Thakur, G.; Naqvi, M.A.; Rousseau, D.; Pal, K.; Mitra, A.; Basak, A. Gelatin-based emulsion gels for diffusion-controlled release applications. J. Biomater. Sci. Polym. Ed. 2012, 23, 645-661. [CrossRef] [PubMed]

74. Joye, I.J.; McClements, D.J. Production of nanoparticles by anti-solvent precipitation for use in food systems. Trends Food Sci. Technol. 2013, 34, 109-123. [CrossRef]

75. Patel, A.R.; Bouwens, E.C.M.; Velikov, K.P. Sodium caseinate stabilized zein colloidal particles. J. Agric. Food Chem. 2010, 58, 12497-12503. [CrossRef] [PubMed]

76. De Paz, E.; Martin, A.; Estrella, A.; Rodriguez-Rojo, S.; Matias, A.A.; Duarte, C.M.M.; Cocero, M.J. Formulation of beta-carotene by precipitation from pressurized ethyl acetate-on-water emulsions for application as natural colorant. Food Hydrocoll. 2012, 26, 17-27. [CrossRef]

77. De Paz, E.; Martin, A.; Bartolome, A.; Largo, M.; Cocero, M.J. Development of water-soluble beta-carotene formulations by high-temperature, high-pressure emulsification and antisolvent precipitation. Food Hydrocoll. 2014, 37, 14-24. [CrossRef]

78. Zhang, Z.P.; Zhang, R.J.; Tong, Q.Y.; Decker, E.A.; McClements, D.J. Food-grade filled hydrogels for oral delivery of lipophilic active ingredients: Temperature-triggered release microgels. Food Res. Int. 2015, 69, 274-280. [CrossRef]

79. Zhang, Z.P.; Zhang, R.J.; Decker, E.A.; McClements, D.J. Development of food-grade filled hydrogels for oral delivery of lipophilic active ingredients: Ph-triggered release. Food Hydrocoll. 2015, 44, 345-352. [CrossRef]

80. Piacentini, E.; Giorno, L.; Dragosavac, M.M.; Vladisavljevic, G.T.; Holdich, R.G. Microencapsulation of oil droplets using cold water fish gelatine/gum arabic complex coacervation by membrane emulsification. Food Res. Int. 2013, 53, 362-372. [CrossRef]

81. Fustier, P.; Achouri, A.; Taherian, A.R.; Britten, M.; Pelletier, M.; Sabik, H.; Villeneuve, S.; Mondor, M. Protein-protein multilayer oil-in-water emulsions for the microencapsulation of flaxseed oil: Effect of whey and fish gelatin concentration. J. Agric. Food Chem. 2015, 63, 9239-9250. [CrossRef] [PubMed]

82. Matalanis, A.; Lesmes, U.; Decker, E.A.; McClements, D.J. Fabrication and characterization of filled hydrogel particles based on sequential segregative and aggregative biopolymer phase separation. Food Hydrocoll. 2010, 24, 689-701. [CrossRef]

83. Matalanis, A.; McClements, D.J. Impact of encapsulation within hydrogel microspheres on lipid digestion: An in vitro study. Food Biophys. 2012, 7, 145-154. [CrossRef] 
84. Firoozmand, H.; Rousseau, D. Microstructure and elastic modulus of phase-separated gelatin-starch hydrogels containing dispersed oil droplets. Food Hydrocoll. 2013, 30, 333-342. [CrossRef]

85. Dickinson, E. Flocculation of protein-stabilized oil-in-water emulsions. Colloids Surf. B Biointerfaces 2010, 81, 130-140. [CrossRef] [PubMed]

86. Mao, Y.Y.; McClements, D.J. Fabrication of functional micro-clusters by heteroaggregation of oppositely charged protein-coated lipid droplets. Food Hydrocoll. 2012, 27, 80-90. [CrossRef]

87. Mao, Y.Y.; McClements, D.J. Modulation of food texture using controlled heteroaggregation of lipid droplets: Principles and applications. J. Appl. Polym. Sci. 2013, 130, 3833-3841. [CrossRef]

88. Mao, Y.Y.; McClements, D.J. Modification of emulsion properties by heteroaggregation of oppositely charged starch-coated and protein-coated fat droplets. Food Hydrocoll. 2013, 33, 320-326. [CrossRef]

(C) 2016 by the authors; licensee MDPI, Basel, Switzerland. This article is an open access article distributed under the terms and conditions of the Creative Commons Attribution (CC-BY) license (http://creativecommons.org/licenses/by/4.0/). 